University of New Hampshire

University of New Hampshire Scholars' Repository

7-15-2016

\title{
Science, scientists, and local weather: Understanding mass perceptions of global warming
}

\author{
Wanyun Shao \\ Auburn University \\ James C. Garand \\ Louisiana State University \\ Barry D. Keim \\ Louisiana State University \\ Lawrence C. Hamilton \\ University of New Hampshire, Durham, lawrence.hamilton@unh.edu
}

Follow this and additional works at: https://scholars.unh.edu/soc_facpub

Part of the Sociology Commons

\section{Comments}

This is the pre-peer reviewed version of the following article: Shao, W., J.C. Garand, B.D. Keim \& L.C. Hamilton. 2016.

"Science, scientists, and local weather: Understanding mass perceptions of global warming." Social Science Quarterly, which has been published in final form at https://dx. doi.org/10.1111/ssqu.12317. This article may be used for noncommercial purposes in accordance with Wiley Terms and Conditions for Self-Archiving.

\section{Recommended Citation}

Shao, W., J.C. Garand, B.D. Keim \& L.C. Hamilton. 2016. "Science, scientists, and local weather: Understanding mass perceptions of global warming." Social Science Quarterly doi: 10.1111/ssqu.12317

This Article is brought to you for free and open access by the Sociology at University of New Hampshire Scholars' Repository. It has been accepted for inclusion in Sociology Scholarship by an authorized administrator of University of New Hampshire Scholars' Repository. For more information, please contact Scholarly.Communication@unh.edu. 
AUTHORS' DRAFT. Final version at:

Shao, W., J.C. Garand, B.D. Keim \& L.C. Hamilton. 2016. "Science, scientists, and local weather: Understanding mass perceptions of global warming." Social Science Quarterly doi: 10.1111/ssqu.12317

\title{
SCIENCE, SCIENTISTS, AND LOCAL WEATHER: UNDERSTANDING MASS PERCEPTIONS OF GLOBAL WARMING
}

\author{
Wanyun Shao \\ Auburn University, Montgomery \\ James C. Garand \\ Louisiana State University \\ Barry D. Keim \\ Louisiana State University \\ Lawrence C. Hamilton \\ University of New Hampshire
}

Authors' note: The authors thank the Pew Research Center for the People and the Press for making available their data from the 2009 Pew General Public Science Survey. We acknowledge that the Center bears no responsibility for the interpretations presented or conclusions that we have reached based on our analyses of these data.

Wanyun Shao is an assistant professor of Geography in the Department of Sociology, Anthropology, and Geography at Auburn University, Montgomery. Address: Auburn University at Montgomery, P.O. Box 244023, Montgomery, AL 36124-4023; Email:wshao@aum.edu.

James C. Garand is the Emogine Pliner Distinguished Professor and R. Downs Poindexter Professor of Political Science at Louisiana State University. Address: 205 Stubbs Hall, Louisiana State University, Baton Rouge, LA 708035433; Email: pogara@lsu.edu.

Barry D. Keim is the Fred B. Kniffen Professor of Geography, Louisiana State Climatologist, and Director of NOAA's Southern Climate Impacts Planning Program at Louisiana State University. Address: E327 Howe-Russell-Kniffen Geoscience Complex, Louisiana State University, Baton Rouge, LA 70803; Email: keim@lsu.edu.

Lawrence C. Hamilton is the Professor of Sociology and a Senior Fellow of the Carsey School of Public Policy at University of New Hampshire. Address: 345D McConnell Hall, 15 Academic Way, University of New Hampshire, Durham, NH 03824; Email: Lawrence.Hamilton@unh.edu.

Direct all correspondence to Wanyun Shao at wshao@aum.edu or Wanyun.Shao@ gmail.com.

Author Wanyun Shao shall share all data and coding for replication purposes. 


\title{
SCIENCE, SCIENTISTS, AND LOCAL WEATHER: UNDERSTANDING MASS ATTITUDES TOWARD GLOBAL WARMING
}

\begin{abstract}
Objective: To explore the effects of long-term climate trends and short-term weather fluctuations, evaluations of scientists and science, political predispositions, religious affiliation, the information environment, and demographic attributes on individuals' views about whether global warming exists and, if so, whether it is a result of natural cycles or human activity.
\end{abstract}

Methods: We use data from the 2009 Pew General Public Science Survey, along with data on long- and short-term patterns of temperature and precipitation in individuals' home communities.

Results: We find that long-term trends in summer temperatures influence perceptions of global warming. Individuals who reside in communities with long-term warming of summer temperatures that are coupled with long-term cooling of spring temperatures are significantly more likely to perceive that global warming exists and is due to human activity. We also find that Americans attitudes toward scientists and science, political dispositions, evangelical religious affiliation, education, and some demographic attributes all have discernible effects on their perceptions of anthropogenic (man-made) global warming.

Conclusion: Individuals' attitudes toward global warming are influenced by long-term temperature trends in their home communities, as well as a variety of attitudinal and demographic attributes. 
There are few topics in American politics today that generate as much controversy as the subject of global warming and climate change. ${ }^{1}$ Americans are sharply divided on this issue. For many Americans, global warming is very real and the result of human activity, and climate change has the potential of generating catastrophic conditions of global proportions. For these Americans, a state of alarm is fully warranted, and complex effects of rising temperatures call for immediate attention and action by both policymakers and the mass public. For other Americans, global warming and climate change is merely "real," insofar as there is some evidence that something is going on with the global climate but also enough uncertainty about the causes of this phenomenon (or even whether it exists) that a state of crisis and alarm is not warranted. For these Americans, humankind is not a major player in climate change, any changes in global climate are due largely to natural cycles that are beyond the control of humankind, and in any event there is little that society can do to affect major changes in the world's climate. Still other Americans deny that climate change exists at all. For these Americans, concerns about global warming are not only unwarranted but rather represent a hyperbolic overreaction by environmental extremists, the scientific community, and the mass media.

The disagreement about climate change in the mass public stands in contrast to the consensus in the international scientific community about both the warming of global temperatures and the view that global warming is due to the cumulative effect of human activity over the past two centuries; indeed, almost $90 \%$ of scientists attribute climate change to human activity (Funk, Rainie, and Page, 2015). How can the views of the mass public and the views of the scientific community be so out of sync? It is likely that Americans' perceptions of climate change and its causes, as well as attitudes toward policies designed to alleviate climate change in the long run, are the result of a confluence of factors, including political attitudes, trust in scientist and science, specific knowledge about climate change, exposure to information about climate change in the media and from other sources, and individuals' own experiences with local weather and climate patterns. Some of these factors-especially political dispositions, attitudes toward science and scientists, and knowledge about climate change—may contribute to a distribution of opinion about climate change within the mass public that differs in stark terms from the consensus of opinion within the scientific community. (See Appendix 1 for a brief discussion of the scientific consensus on climate change and differences in perceptions by the mass public.)

In this paper we explore the role of local weather fluctuations and climate trends, science beliefs, and other social and cognitive predictors in shaping perceptions about climate change. For instance, does local weather and 
climate help to understand why some Americans are convinced that global warming is a major problem confronting the planet, while still other Americans are either ambivalent or deny its existence? Recently other scholars, using a variety of models and datasets, have explored such questions (cf., Egan and Mullin, 2012; Hamilton and Keim, 2009; Hamilton and Stampone 2013; Kellstedt, Zahran, and Vedlitz, 2008; Lorenzoni and Pidgeon, 2006; Shao, Keim, Garand, and Hamilton 2014). We build on this body of research by considering the effects of a wide range of predictor variables, but we focus particular attention on the effects of long- and short-term patterns of local weather and climate, as well the role of beliefs about science and scientists. We find that both positive attitudes toward science and scientists, as well as long-term seasonal temperature trends in individuals' local environments, have a discernible effect on how Americans perceive global warming and its causes.

\section{Previous Research on Mass Attitudes and Perceptions About Climate Change}

What explains variation in individuals' attitudes toward and perceptions of global warming and climate change? Previous studies have identified several theoretical clusters of variables as determinants of public opinion towards global warming: (1) geographic and environmental context; (2) attitudes toward scientists and science; (3) political predispositions and attitudinal variables; (4) the information environment; (5) religious beliefs and attachments; and (6) socioeconomic and demographic characteristics.

Geographic and environmental context. That weather could affect how individuals think about climate change makes some sense. The role of local weather has a storied history in studies of American electoral behavior, with the conventional wisdom that bad weather on election day decreases voter turnout and favors Republicans in American elections finding considerable empirical support (Gomez, Hansford, and Krause, 2007). Regarding public perception of global warming, the effect of local weather has been estimated in several studies. Personal observation of local weather (Borick and Rabe 2010; Krosnick et al. 2006; Myers et al. 2013), short-term weather fluctuations (Egan and Mullin 2012; Hamilton and Stampone 2013; Howe et al. 2013), and long-term temperature trends (Hamilton and Keim 2009; Shao et al. 2014) have all been found to have significant effects on public perception of global warming. Further, Hamilton and Stampone (2013) and Egan and Mullin (2012) find evidence that the effects of local shortterm weather fluctuations on perceptions of global warming vary systematically by partisanship and ideology. It appears that local weather plays a role in shaping individuals' attitudes toward and perceptions of global warming.

Attitudes toward scientists and science. The scientific community has been the primary advocate for the view that climate change is occurring and that it is the result of human activity, so it would not be surprising that how 
Americans think about scientists and science would affect their views of climate change. Indeed, Malka, Krosnick, and Langer (2009) find that trust in scientists has a powerful effect on the conversion of knowledge about global warming into perceptions of how serious climate change is as a problem. On the other hand, Kellstedt et al. (2008) find that confidence in science is negatively related to concern with climate change; they suggest that this reflects confidence that scientists will be able to come up with workable solutions for dealing with climate change.

Political Predispositions and Attitudinal Variables. How individuals think about politics also influences how they think about global warming. The perception that global warming exists and is due to human activity leads many observers to the inexorable conclusion that effective government regulation of the emission of greenhouse gases is necessary. For many, this means a substantial involvement of government in the regulation of individuals and the economy, such as the adoption of a carbon tax or cap-and-trade policies. Hence individuals who are skeptical of governmental power and who favor individualism over collective action would be less likely to perceive that global warming is a problem and to support government action to combat global warming. In contrast to liberals, conservatives tend to favor individual freedom in the economic sphere and private property rights over collective rights, as well as free market over governmental intervention, so we would expect conservatives to be more skeptical than liberals of anthropogenic global warming. In previous research scholars have found that Republicans and conservatives are more likely to be skeptical of anthropogenic global warming than Democrats and liberals, and therefore these groups show lower levels of concern about global warming (Shao et al. 2014; McCright and Dunlap 2011b; Malka et al., 2009; Dunlap and McCright 2008; Pew Research Center 2006, 2007; Gallup 2008). Moreover, education has been found to have different effects on risk perception of global warming among Democrats and Republicans. While concern about global warming has been found to increase with the level of education among Democrats or liberals, these concerns decrease or are invariant with the level of education among Republicans or conservatives (McCright and Dunlap 2011b; Hamilton and Keim 2009; Hamilton 2008, 2011, 2012; Pew Research Center 2007). It would appear that partisanship has a direct effect on attitudes toward global warming, but partisanship also serves to filter information about global warming.

Information Environment. Because the scale of global warming transcends personal experience, public understanding of this phenomenon is reliant on a variety of information sources. The role of the media has drawn particular attention in the scholarly literature. Indeed, the mass media's pursuit of "balance" by employing "dueling scientists" to cover both sides has helped to maintain the public impression of broad scientific disagreement about 
the reality of global warming (Boykoff 2008; Boykoff and Boykoff 2004; Dunlap 1998). Moreover, previous studies produce confusing results about the effect of attention on public perception of global warming; Kellstedt et al. (2008) find that the level of information about global warming is negatively associated with concern about this issue, while Wood and Vedlitz (2007) find that respondents who are more attentive to global warming have higher level of concern about this issue. Trust in these information sources also comes into play as an important moderating force (Malka et al. 2009). Krosnick et al. (2006) find that television exposure is positively associated with belief in the existence of global warming only among individuals who have high level of education and show more trust in scientists. Finally, education has usually been hypothesized to be positively associated with environmental concern, but empirical tests have generated mixed results. Arguably, individuals with high levels of education are better informed about environmental matters and are more sensitive to perceptions of risk than others. Hamilton (2008, 2011 , 2012) provides support for this hypothesis, showing that higher levels of education are associated with greater concern or belief in the reality of climate change. Egan and Mullen (2012) find that individuals who have completed post-graduate work are more likely to perceive that there is "solid evidence" of global warming.

Religious beliefs and attachments. The role of religion in shaping Americans' attitudes toward climate change has drawn some scholarly attention in recent years. The argument is that the teachings of many religions stress the role of stewardship in describing the relationship between human society and nature. Jones, Cox, and NavarroRivera (2015) document basic differences in concern about climate change across religious affiliations, with white evangelical Christians (35\%) exhibiting the lowest level of concern, followed by white Catholics (41\%) and mainline Protestants (43\%) as groups with less than 50\% of adherents saying that they are "very concerned" or "somewhat concerned." For other religious affiliations, a majority of adherents express some level of concern with climate change: Jews (53\%), the non-Christian religious (56\%), black Protestants (58\%), the religious unaffiliated (60\%), and Hispanic Catholics (73\%). The finding that American evangelicals are less concerned by climate change is reinforced by Smith and Leiserowitz (2013). Moreover, scholars have explored evidence for the "greening of Christianity" (Van Dyke, Mahan, Sheldon, and Brand, 1996; Wilkinson, 2010, 2012; Clements, McCright, and Xiao 2014). The study of the role of religion in influencing attitudes toward climate change is likely to develop further as debates about Pope Francis' recent climate change encyclical are played out in the near future.

Socioeconomic and Demographic Characteristics. Numerous scholars have explored the effects of socioeconomic and demographic factors on public perceptions of and attitudes toward climate change (cf., Brody, Zahran, 
Vedlitz, and Grover, 2008; Dietz, Dan, and Shwom, 2007; Dunlap and McCright, 2008; Hamilton and Keim, 2009; Hamilton 2012; Krosnick et al. 2006; Leiserowitz 2006; Shao et al. 2014). First, the effects of race and gender appear to be relatively stable across studies of public perception and attitudes relating to global warming. Racial minorities and women are typically found to have higher levels of public concern about climate change (Leiserowitz, 2006; Malka et al. 2009; McCright and Dunlap, 2011b; Shao et al. 2014). Second, the effect of age on public attitudes towards global warming is usually found to be negative, indicating that older individuals tend to show lower levels of concern for global warming (Hamilton 2012; Hamilton et al. 2012; Kellstedt et al. 2008; Krosnick et al., 2006; Malka et al., 2009; McCright and Dunlap, 2011b; Shao et al, 2014). Third, income and other variables relating to social class have been hypothesized to be negatively related to attitudes toward global warming. This may well be due to the high costs likely to be borne by individuals with high incomes should policies designed to combat global warming be adopted. In previous research income has a negative effect on public risk perceptions of climate change (Hamilton and Keim 2009; Shao et al., 2014) and concern for this issue (McCright and Dunlap 2011b), though Hamilton (2008) shows that higher levels of income are associated with greater concern for some impacts of global warming.

\section{DATA AND METHODS}

We investigate the effects of geographic and environmental context, attitudes toward scientists and science, political predispositions and attitudinal variables, the information environment, religious beliefs and attachments; and socioeconomic and demographic characteristics on individuals' perceptions of global warming. Our strategy is to combine survey data with aggregate weather and climate data linked to the geographic areas within which survey respondents reside. In order to explore the determinants of individuals' perceptions of global warming, we rely on data from the 2009 Pew Research Center for the People and the Press General Public Science Survey, conducted nationally from April 28 to May 12, 2009 for a representative sample of 2,001 individuals aged 18 years or older (Pew Research Center, 2009). This survey includes a rich set of variables, including items that specifically ask respondents' about their perceptions of global warming. The survey also asked respondents a series of questions that permit us to measure key independent variables. Moreover, the geographic information collected at the zip code level permits us to identify the geographic context within which each respondent resides so that we can merge local weather data with survey data. (For more detail on how we merge survey and contextual data, see Appendix A2.) 
What are the components of our model of individuals' perceptions of global warming? We discuss here the independent variables used in our model of public opinion towards global warming. A brief summary of the variables used in this analysis and their coding can be found in Appendix Table A2, and descriptive statistics for these variables are presented in Appendix Table A3.

\section{Dependent Variable}

The dependent variable in our models is based on responses to the following question asked in the 2009 Pew General Public Science Survey: "Which of these three statements about the earth's temperature comes closest to your view?" This variable is coded 0 for those who respond that "the earth is not getting warmer," 1 for those who respond that "the earth is getting warmer mostly because of natural changes in the atmosphere," and 2 for respondents who indicate that "the earth is getting warmer mostly because of human activity such as burning fossil fuels." Among these three views on global warming, $87.5 \%$ of respondents believe in either natural or anthropogenic global warming, while only $12.5 \%$ do not believe global warming is occurring. This suggests that the large majority of the public accepts that global warming is a reality. Among those who believe that global warming is taking place, whether global warming is mainly anthropogenic or natural is hotly debated. Indeed, $37.2 \%$ of respondents believe that the earth is warming mainly because of a naturally-occurring cycle, while $50.3 \%$ believe that the earth is warming mainly because of human activities. Only about 50\% of the public accepts the scientific consensus that global warming is occurring and is the result of processes influenced by human activity.

A detailed justification for this measure can be found in Appendix 3.

\section{Independent Variables}

Local weather and climate. We consider the effects of local weather and climate on individuals' perceptions of the existence of global warming and that global warming is attributed to human activity. One of the problems with studying the effects of objective weather and climate on perceptions of climate change is in determining the proper time horizon for considering these effects. There are plenty of data on weather conditions at the local level and over extensive time periods, but it is unclear at which temporal level weather influences how individuals perceive their local climate. What makes the strongest impression in the minds of individuals as they consider local weather and climate conditions? Are individuals influenced by weather patterns in the short term-i.e., in the past few days or weeks? Are individuals more likely to perceive that climate change is occurring if temperatures in the past few days are unseasonably warm? Alternatively, are individuals aware of long-term climate trends in the local 
environments - say, over the past 10 or 20 years — and do these trends affect how they think about climate change? Or do individuals consider and take notice of comparisons in weather or climate patterns across seasons—-for instance, from cold winters or springs to warm summers? Do unseasonably cold and warm seasons draw the attention of individuals in their thinking about climate change?

Different scholars use different time horizons in estimating the effects of weather and climate on perceptions of climate change, but to date there are no firm theoretical reasons presented in the literature to favor one time horizon over another. We suggest that there are two temporal attributes of information and personal experiences that may underlie the effects of weather and climate on individuals' perceptions of climate change. The first is temporal proximity - i.e. the degree to which individuals have experienced or been exposed to information about notable weather patterns in the recent past. With all else equal, human memory favors proximate events over those that are in the distant past, so one might expect recent weather events or patterns to be more easily and accurately retrieved from memory and hence play a bigger role in shaping individuals' perceptions of climate change. For instance, individuals who experience unseasonably warm temperatures over the past few days are much more likely to remember those temperatures and that they are unusually high than if they experienced unusually warm temperatures for a single week 10 or 20 years ago.

The second temporal attribute of information and personal experiences that might relate to perceptions of climate change is long-term temporal consistency. When members of the scientific community discuss climate change or global warming, they are not talking about temperature deviations that have been observed over the period of a few days or weeks. Rather, scientific discussions of climate change focus on long-term patterns of temperature, precipitation, and other weather events. Hence short-term weather fluctuations are not evidence of climate change. When individuals experience short-run climate patterns in their local environments that deviate from long-term patterns, they integrate these experiences into their short-term memory, but when climate patterns return to normal the unusual experiences eventually are either forgotten or are else more difficult to retrieve from memory. However, when these short-term deviations from the previous normal pattern are repeated over an extended time period, individuals' experiences (and resulting memories) of unusual local climate patterns begin to accumulate, and over the long run individuals begin to realize that the change in weather patterns may actually represent a change in longterm climate. We suggest that individuals who reside in geographic localities that experience long-term, consistent patterns of climate change (i.e., those that are consistent with scientific evidence of global warming) will be more 
likely to perceive local climate change and attribute these long-term climate shifts to global climate change. On the other hand, individuals who reside in localities that experience stable climate patterns over time will have little in their collection of personal experiences to support assertions of global climate change.

In order to explore the effects of weather and climate patterns on perceptions of global warming, it is necessary to measure local weather and climate variables in a way that captures different time horizons through which weather and climate could influence individuals' thinking about climate change. We begin by creating four seasonal temperature and four seasonal precipitation trends using data from the United States Historical Climate Network (USHCN). These trends are measured for the Winter (December, January, February), Spring (March, April, May), Summer (June, July, August), and Fall (September, October, November) and are based on the mean seasonal temperatures for each year. These trend variables are calculated using data over the past 10 years prior to the survey date. ${ }^{2}$ Considering that the survey was conducted from April $28^{\text {th }}-$ May $12^{\text {th }}, 2009$, for winter and spring we calculate temperature and precipitation trends from 2000 to 2009, while for summer and fall we calculate trends from 1999 to 2008 to capture the long term climate trends in each respondent's immediate environment. Specifically, we regress the average seasonal temperature or precipitation for a particular season on year, and we use the unstandardized bivariate regression coefficient to represent seasonal trends.

Our hypotheses relating to these long-term local temperature indicators are quite simple, insofar as we suggest that positive trends in temperatures for each season are positively associated with public perceptions of global warming. We speculate that individuals who experience rising seasonal temperatures in their home communities over the past 10 years are more likely to believe that global warming is occurring and mainly human induced. ${ }^{3}$ For our precipitation trend variables, the hypothesized directions are less clear, so we test the coefficients for these variables using statistical criteria associated with non-directional hypotheses.

In addition, we capture short-term weather fluctuations by including two weather measures: (1) average temperature departure from normal temperature during April 2009, which is the month prior to the survey dates, and (2) average precipitation departure from normal precipitation, also during April 2009.4 To account for relative weather fluctuation in different regions, these departures are normalized (i.e., measured in standard deviation units).

Attitudes towards scientists and science. We suggest that the attitudes towards scientists can have important effects on individuals' perceptions of global warming. Individuals who have positive views toward scientists and who perceive that there is a scientific consensus about global warming are more likely than others to perceive that 
global warming is a problem. To capture these effects, we include three independent variables in our models. First, we measure individuals' general evaluations of scientists' contributions to society, coded from 0 (nothing at all) to 3 (a lot). We hypothesize that this variable is positively associated with the dependent variable, indicating that those with positive views about scientific contributions are more likely to perceive that global warming is taking place and that it is caused by human activity. Second, scientists' ideology reflects respondents' perceptions of the ideological position of scientists and is measured as a three-point scale ranging from -1 (scientists are liberal) to 1 (scientists are conservative). Because perceptions of global warming are perceived to involve an environmentalist or liberal world view, some critics perceive that global warming is exaggerated (at best) or manufactured (at worst) by liberal scientists to force environmental action on the American political system. Given this, we hypothesize that the coefficient for this variable will be positive, indicating that individuals who perceive that scientists are conservative (liberal) will be more (less) likely to perceive the existence and severity of global warming. Third, we speculate that people who believe there is a consensus on global warming among scientists would be more likely to accept global warming and the argument that global warming is mainly caused by human activity. This variable is coded 1 for those who perceive that "scientists generally agree that the earth is getting warmer" and 0 for those who disagree. The coefficient for this variable is expected to be positive.

We also include two items from the Pew Science Survey that capture the attitudes of the mass public towards science in general. The first variable represents the degree to which individuals perceive that scientists have a positive effect on American life. This variable is a scale derived from a factor analysis of three items: (1) science effects on society, which is coded as a three-point scale, ranging from -1 (mostly negative) to 1 (mostly positive); (2) science effects on life, which is coded as a three-point scale ranging from -1 (science makes life more difficult) to 1 (science makes life easier); and (3) science effects on the environment, which is also a three-point scale ranging from -1 (mostly negative) to 1 (mostly positive). All three items load on one factor (eigenvalue $=1.513$; variance explained $=0.504)$. We speculate that people who perceive that science has positive effects will be more likely to believe that global warming is occurring and/or is a result of human activity. A second indicator of individuals' attitudes toward science represents whether respondents perceive that government investments in basic scientific research usually pays off in the long run; this variable is coded 1 for those who agree that government investments in scientific research pay off, and 0 otherwise. We hypothesize that greater confidence in scientific research promotes individuals' beliefs in anthropogenic global warming. 
Political Predispositions. We include two political attitudinal variables in our models, partisan identification and ideology, both of which have been shown to be important predictors of perception of global warming. We measure partisan identification by combining two items from the Pew Survey—one measuring the direction of partisanship, and the other measuring the degree to which professed independents lean toward one party or the other. The result is a partisanship variable that is measured on a five-point scale, ranging from 0 (Democrat) to 4 (Republican). Moreover, we measure respondents' self-reported ideology based on a five-point scale, ranging from 0 (very liberal) to 4 (very conservative). We hypothesize that people who are conservative and are Republicans are more likely to be skeptical of anthropogenic global warming and global warming more generally. Finally, because previous studies have shown that partisanship interacts with education to generate variation in perceptions of global warming (McCright and Dunlap 2011b; Hamilton 2011, 2012; Hamilton and Keim 2009), we include an interaction variable for partisan identification and education in our models. We hypothesize that in our interaction models the (non-interaction) coefficients for education will be positive, indicating the effects of this variable for Democratic partisans (i.e., for whom partisan identification is equal to 0 ). The coefficients for our interaction variable is expected to be negative, indicating that as individuals become more Republican the effect of education on perceptions of global warming becomes less positive and, for the strongest Republican partisans, possibly negative.

Information Environment. The issue of global warming is complex, and individuals' perceptions on this issue will be at least partly a function of the information to which they are exposed. Individuals who are knowledgeable about public affairs and science, as well as individuals who are exposed to information about global warming, should be more likely to perceive that global warming exists and/or is a result of human activity.

Any study of the effects of the information environment on perceptions of global warming should start with education. We measure education on a seven-point scale, ranging from 0 (respondent has completed 8 grades or less and no diploma) to 6 (respondent has earned a post-graduate degree). We hypothesize that individuals with higher levels of education are more likely to perceive global warming and to attribute it to human activity. Hence the coefficient for this variable should be positive, though as noted this effect may be moderated by partisanship.

Second, we use a survey item that specifically measures respondents' knowledge about global warming by asking respondents about this basic scientific fact: "What gas do most scientists believe causes temperatures in the atmosphere to rise?" We code this variable 1 for respondents who provide the correct answer (i.e., carbon dioxide), and 0 for other respondents. We hypothesize that individuals with sufficient knowledge about global warming that 
they are able to correctly recall the correct answer are more likely to accept both global warming (in general) and anthropogenic global warming.

Third, we consider the effects of media use, suggesting that individuals who are heavy media users may be either more or less likely to perceive global warming as a matter of concern. We measure both general media use and attention to science news on four-point scales, with each ranging from 0 (not at all enjoy keeping up with news) to 3 (enjoy keeping up with news a lot). The third variable, which we denote as "scientific media use," is based on a factor analysis of three items: (1) "Do you regularly watch television programs or channels about science such as Nova or Discovery Channel, or not?" (2) “Do you regularly visit science web sites and blogs, such as NOAA.gov or ScienceDaily.com, or not?” (3) “And do you regularly read science magazines, such as Popular Science or Scientific American, or not?" All three of these variables are binary variables, coded 1 (regularly) and 0 (not regularly). We find that these items load on a single dimension (eigenvalue $=1.418$, variance explained $=0.473$ ) Because there is some dispute in the literature about the direction of the effects of media use, we employ a twotailed test in evaluating the coefficients for these media variables.

Religious beliefs and attachments. In order to capture the possible effects of religion, we include in our models a series of dichotomous variables representing each of the following religious groups: (1) white evangelical Protestants; (2) black Protestants; (3) mainline Protestants; (4) Catholics; (5) other Christian; (6) Jewish; (7) Mormon; (8) other religion; and (9) secular. Each of these variables is coded 1 for respondents who are members of the specific religious group, and 0 otherwise. Following previous research, we hypothesize that white evangelicals will be the least likely to perceive that climate change is occurring and/or is due to human activity, so this is the excluded (contrast) group in our models. Hence we hypothesize that the coefficients for the other religious group variables will be positive. Moreover, we include in our model a measure of respondents' frequency of religious service attendance, which reflects the possibility that individuals will be exposed to alternative information sources that may downplay the certainty of science. This variable is measured on a scale ranging from 0 (never attend services) to 5 (more than once a week). The frequency of attending religious service has been shown to have a negative effect on the perception of local effects from climate change (Hamilton and Keim 2009; McCright and Dunlap 2011b). Hence we posit that individuals who attend religious services more often are less likely to believe in anthropogenic global warming or global warming in general. 
Demographic characteristics. These variables serve as control variables in our models. First, we posit that individuals' perceptions of global warming are shaped by race and gender. In previous studies scholars have shown that racial minorities and women are more sensitive to and concerned about risks due to their vulnerabilities. Given this, we create two separate binary variables to represent race $(1=$ white; $0=$ other $)$ and gender $(1=$ women; $0=$ men). We hypothesize that the coefficients for race in our various models are negative, while the coefficients for gender are positive. Second, we include income and age in our models. We measure income on a scale ranging from 1 (respondent earned less than $\$ 10,000$ ) to 9 (respondent earned $\$ 150,000$ or more). We hypothesize that there will be a negative relationship between income and perceptions of global warming. We also measure respondents' age in years, ranging from 18 to 95 years. As suggested by previous research, we speculate that older people are less likely to believe in global warming and to perceive that global warming is due to human activity.

\section{EMPIRICAL RESULTS}

As a starting point, in Model (1) of Table 1 we report estimates for our model of individuals' perceptions of global warming to include individual-level attributes but without our measures of climate and weather. In Model (2) we add the contextual climate variables to the model. Both models perform well in general terms; the pseudo- $\mathrm{R}^{2}$ values in the models are 0.226 and 0.233 , respectively, and the Wald $\chi^{2}$ statistics are highly significant, indicating that the models do a much better job at predicting individuals' perceptions of global warming than what one would expect by chance. ${ }^{5}$ We focus our attention on the results from Model (2) and include the results from Model (1) for purposes of comparison.

\section{Long- and Short-Term Climate and Weather Effects}

We begin by considering the effects long- and short-term climate and weather effects. In Model (2) of Table 2 we report the results for a model that permits us to explore the effects of various climate and weather variables on perceptions of global warming. Here our analytical strategy is to add to our core model a series of variables that capture long-term (10-year) trends in temperature and precipitation in our survey respondents' local communities for each of the four seasons, as well as short-term fluctuations in weather patterns. As one can see from a comparison of the results from Models (1) and (2), there is little difference in the magnitude and significance of the coefficients for the variables from our core model.

The effects of 10-year climate trends and short-term weather deviations are generally quite modest. First, none of the coefficients for the variables representing 10-year seasonal precipitation trends are statistically significant; 
simply, upward or downward trends in precipitation over the past 10 years are unrelated to how individuals perceive global warming. It would appear that precipitation trends in individuals' local communities is not a major consideration as they are developing their perceptions of anthropogenic global warming. Second, short-term departures from normal temperatures and normal precipitation (i.e., departures over the month prior to the survey dates) are also unrelated to the dependent variable. While two other studies (Egan and Mullin 2012; Hamilton and Stampone 2013) report short-term temperature effects on climate-change beliefs, we do not see such effects in these data. Our findings are not necessarily incompatible with those of these other scholars, since our measure of "shortterm" weather fluctuations covers a longer time frame than in these other works. Our measure captures the effects of weather in the recent past, as opposed to the immediate past.

What we do find is some mixed evidence about the effects of long-term trends in seasonal temperatures on perceptions of global warming. We speculate that increases in winter temperatures would have a strong effect on global warming perceptions, but this is not the case $(b=-0.027, z=-0.75)$. It appears that individuals who reside in geographic areas with an upward trend in winter temperatures are no more or no less likely to perceive that global warming exists and is due to human activity. Our coefficients for fall temperatures trends are also small and statistically nonsignificant. Surprisingly, the coefficient for spring temperature trends is negative, though it barely misses conventional levels of statistical significance in a two-tailed test $(b=-0.159, z=-1.88)$. However, we do find evidence that upward trends in summer temperatures have an effect on perceptions of anthropogenic global warming $(b=0.123 ; z=1.74)$. In Appendix Figure A4 we present the predicted probabilities for our three global warming outcomes as a function of summer temperature trends; based on these results, one can see that increases in summer temperature trends result in an increase in the probability that one perceives that global warming is due to human activity and a decrease in the probability of perceiving no global warming or global warming based on natural cycles. The increase in the probability of perceiving anthropogenic global warming is not trivial; as they move from the lowest to the highest trend in local summer temperatures, individuals increase the probability of perceiving that global warming is due to human activity by about 0.20 .

While it appears that summer temperature trends have a positive effect on individuals perceptions of anthropogenic global warming, one other possibility is that individuals' perceptions of global warming may be sensitive to temperature trends that show greater disparity from one season to the next. We see that warmer summer temperatures in individuals' communities increase the perceptions of anthropogenic global warming, but there is a 
tantalizing hint — albeit, not a statistically-significant one by conventional standards — that cooling spring temperatures have the same effect. Is it possible that perceptions of anthropogenic global warming may be responsive to greater disparities in trends for summer and spring temperatures? Are perceptions that global warming is due to human activity more likely to develop for individuals who reside in communities with matched trends toward cooling spring temperatures but warming summer temperatures_-and, hence, growing summer-spring temperature disparities? Is it this pattern of temperature disparities in adjacent seasons over time that creates longterm temporal consistency sufficient to stand out in individuals' memories and hence shape their thinking about climate change? It may well be the case that the meaning of trends toward warmer summer temperatures in individuals' minds depends not only on a comparison of summer temperatures from one year to the next but also on a contrast between summer and spring temperatures. When summer temperatures are increasingly high compared to spring temperatures, individuals may be more likely to perceive that climate is changing and convert those observations into perceptions about anthropogenic global warming.

To consider this possibility, we create a variable by calculating the difference in the summer and spring temperature trends; a high score on this variable means that the 10 -year trend in summer temperatures in an individual's community is much greater than the 10-year trend in spring temperatures. To simplify our model, we drop all of the other contextual weather and climate variables, none of which are shown to have a significant effect on perceptions of global warming. Our findings are presented in Table 2 and confirm our speculation that an increasing gap in summer and spring temperature trends over time has a strong positive effect on individuals' perceptions of anthropogenic global warming $(b=0.145, z=2.70)$. Individuals who are experiencing rising trends in summer temperatures relative to the trend in spring temperatures are significantly more likely to develop the perception that global warming is occurring and mainly due to human activity. It would appear that if individuals are observing a trend toward cooler spring temperatures, then an associated trend toward warmer summer temperatures would mean that the higher summer temperatures stand out and are more likely to be remembered and integrated into their climate perceptions. This would accentuate the effects of higher summer temperatures on perceptions of global warming. In Appendix Figure A5 we present the pattern of predicted probabilities for the three outcomes on our dependent variable as a function of the difference in summer-spring temperature trends, and one can see that moving from the lowest to highest values on this independent variable increases the probability that an individual perceives anthropogenic global warming by 0.31 - i.e., from 0.36 to 0.67 . Simply, individuals who reside in 
communities where there is a trend toward bigger spring-summer temperature swings are significantly more likely to perceive that global warming exists and is due to human activity. This is strong evidence that long-term local temperature trends in individuals' local communities can help shape their views toward global warming.

One caveat that might be expressed about this analysis is that not all individuals residing in a given county when the Pew survey was conducted have lived there for a long enough time to experience the 10-year climate pattern. Arguably, our ordered logit estimates represent average effects across all individuals, regardless of whether they have lived in their present location for 10 years or more. However, one might expect the effect of 10 -year trends in spring-summer temperature swings to be stronger for those residing in their home counties for at least 10 years than for those who are "new" residents of less than 10 years. In Appendix 4 we present a detailed consideration of this possibility, using age as a proxy for length of residence. We find that older survey respondents are significantly responsive to differences in long-term spring-summer temperature trends, while younger respondents are not. Our findings provide indirect support for the argument that exposure to long-term temperature trends may have an effect on individuals' perceptions of climate change.

Attitudes toward scientists. Turning back to Model (1) in Table 1, we find that how individuals perceive scientists has a strong and consistent effect on how individuals think about global warming. Individuals who perceive that scientists make a strong contribution to the well-being of society are significantly more likely to accept anthropogenic global warming; the coefficient for this variable is positive and significant $(b=0.309, z=2.12)$. Moreover, the effect of this variable can be seen in Appendix Figure A6, in which we report predicted probabilities for each of the three outcomes on the dependent variable as belief in scientists' contributions increases, holding constant the effects of other independent variables. As one can see, perceptions of contributions by scientists have a strong positive effect on perceptions that global warming exists and is due to human activity. Second, we find that perceptions of scientists' ideological leanings have a modest effect on how individuals perceive global warming. As individuals perceive scientists to be more conservative, they become more likely to perceive that global warming exists $(b=0.267, z=2.03)$. Conversely, individuals who perceive that scientists are liberal are less likely to perceive that global warming is generated by human activity. This is in keeping with the perceptions held by some individuals that scientists are an ideological liberal group and that their findings are tainted by ideological bias.

Perhaps the most powerful variable in our models is individuals' perceptions that there is a scientific consensus about global warming. Those individuals who perceive that scientists are in agreement that "the earth is getting 
warmer because of human activity" are significantly more likely to believe in anthropogenic global warming $(b=$ $1.586, \mathrm{z}=11.28)$, suggesting that individuals consider the degree to which there is a scientific consensus in shaping their own views on global warming. Indeed, we can see from Appendix Figure A7 that individuals who perceive a scientific consensus are about twice as likely to believe that global warming is due to human activity as those who do not perceive a scientific consensus. These results suggest the possibility that having dissenting voices in debates over global warming may create for some individuals sufficient doubt in anthropogenic global warming.

Not only do we propose that attitudes toward scientists will shape global warming perceptions, but we also suggest that how individuals perceive science will have a similar effect. Contrary to expectations we find little evidence that individuals' perceptions of positive effects of science on various aspects of American life (i.e., "society," "making life easier," and "the environment) influences how they think about global warming (b = -0.050, $\mathrm{z}=-0.55)$. On the other hand, we find that individuals who perceive that investments in "basic scientific research" usually pay off are more likely to accept the scientific consensus in support of anthropogenic global warming $(b=$ $0.790, \mathrm{z}=4.08)$. The perception that science has positive societal payoffs creates the impression of scientific credibility and promotes perceptions that global warming exists and is due to human activity.

Political predispositions. The effects of political ideology and partisanship on perceptions of global warming are generally as expected. First, we hypothesize that there is a negative relationship between conservative ideology and perceptions of anthropogenic global warming, and our results provide strong support for this assertion (b $=-0.298, \mathrm{z}=-3.46$ ). This effect can be visualized in Appendix Figure A8, in which we present the predicted probabilities for each of the three outcomes on the dependent variable that are associated with each outcome on the political ideology variable. As one can see, political conservatives are significantly less likely than political liberals to perceive anthropogenic global warming, and they are significantly more likely to perceive that global warming is due to natural cycles or does not exist at all.

The effect of partisan identification on perceptions of global warming is a bit more complicated, insofar as partisanship mediates (and is mediated by) education. At a simple level, partisanship is expected to have a negative effect on perceptions of global warming, since Republicans are less likely to perceive that global warming either exists or is due to human activity. This can be confirmed by the partisan identification coefficient in a model that specifies an additive effect of partisanship $(b=-0.325, z=-6.86$, full model results not shown). This additive effect of partisan identification can be shown in Appendix Figure A9, with Republican partisans less likely to perceive 
anthropogenic global warming but more likely to perceive that global warming is due to natural cycles or does not exist at all. However, we consider explicitly the possibility that that the effect of education on perceptions of global warming varies as a function of individuals' partisanship, as documented by other scholars (McCright and Dunlap 2011b; Hamilton 2011, 2012; Hamilton and Keim 2009). In Model (2) of Table 1 we include variables for partisan identification, education, and the interaction for partisanship and education. With the interaction included in the model, the coefficient for education represents the effect of education for Democrats (i.e., those who are coded 0 on partisanship); the coefficient for the party * education interaction reflects how the effect of education changes as individuals move by one unit in the Republican direction. As one can see, the coefficient for education is positive and highly significant $(b=0.244, z=3.92)$, indicating that for Democrats increases in education are related positively to perceptions of anthropogenic global warming. On the other hand, the coefficient for the interaction variable is negative $(b=-0.064, z=-2.69)$, indicating that increases in (Republican) partisanship results in a weakening of the relationship between education and perceptions of global warming. Indeed, in Appendix Figure A10 we present the pattern of predicted probabilities for perceptions of anthropogenic global warming as a function of education, presented separately for strong Democrats and strong Republicans. These results show that for strong Democrats there is a strong positive effect of education on perceptions of anthropogenic global warming; as strong Democrats become more educated, they are much more likely to perceive that global warming exists and is a result of human activity. On the other hand, for strong Republicans there is no relationship between education and perceptions of anthropogenic global warming. Strong Republicans with both high and low education levels hold the same mean predicted probabilities of perceiving that global warming is due to human activity. It is also the case that increases in education are associated with a greater disparity in perceptions of anthropogenic global warming for Democrats and Republicans, suggesting that the effects of partisanship increase with higher levels of education.

Religious variables. We find some evidence of religion effects, primarily in comparing white evangelical Christians and other groups. White mainline Protestants are significantly more likely than white evangelical Christians to perceive anthropogenic global warming $(b=0.749, \mathrm{z}=2.97)$, as are Jews $(b=1.094, \mathrm{z}=2.24)$. Moreover, in our model estimated without our local climate variables, Mormons are also found to be more likely to perceive anthropogenic global warming $(b=1.218, \mathrm{z}=2.09)$, though this effect decreases to statistical nonsignificance when we add the local climate variables to our model. It would appear that white evangelical Christians are somewhat less likely to perceive anthropogenic climate changes, once we control for the effects of 
other variables (including political ideology and partisan identification). ${ }^{6}$ Finally, church attendance is found to be statistically unrelated to perceptions about global warming.

Information environment. Given the state of climate science and the wide-spread reports of a scientific consensus over global warming, we speculate that individuals' exposure to information should have a positive effect on their perceptions that global warming exists and is attributable to human activity. Turning to the model estimates in Model (2), we find that none of the independent variables in the information environment cluster have a significant effect on perceptions of global warming. Knowledge of global warming and the three media variables all have coefficients that fail to achieve standard levels of statistical significance. It appears that information effects reside in the effects of individuals' level of education, though this effect is primarily among non-Republicans

Demographic attributes. There is some evidence that demographic characteristics are related to perceptions of global warming. First, the coefficient for age is both negative (as expected) and statistically significant $(b=-0.010, z$ $=-2.22$ ); this suggests that older individuals are more likely to be skeptical of global warming than those who are younger. Second, consistent with previous studies, we find that women are significantly more likely to perceive that there is anthropogenic global warming $(b=0.283, \mathrm{z}=1.90)$ Third, we find little evidence that race is related to perceptions of global warming $(b=-0.337, z=-1.193)$. This null finding stands in some contrast to the findings of other scholars. ${ }^{7}$ Finally, income is negatively related to global warming perceptions $(b=-0.060, z=-1.72)$; individuals with higher incomes are less likely to perceive that global warming exists and is due to human activity than those with lower incomes. This is in keeping with the argument that high-income individuals are likely to recognize the high costs that are associated with addressing anthropogenic global warming.

\section{SUMMARY AND CONCLUSIONS}

In this paper we explore the determinants of Americans' perceptions of global warming. We develop a model in which we depict global warming perceptions as a function of several clusters of independent variables, including the long-term climate and short-term weather in individuals' home communities, attitudes toward scientists and science, political predispositions, religious variables, the information environment, and demographic attributes. We use data from the 2009 Pew Public Science Survey, which includes a wide range of variables representing the interplay of science, politics, and policy.

What have we learned about the determinants of Americans' perceptions of global warming? First, we suggest that, over time, trends toward higher temperatures may cumulate to form effects that go beyond the effects of 
weather patterns in the recent past, and we find that seasonal temperature trends in the medium-term (i.e., over the past 10 years) show some effects on public perceptions about global warming. Increasingly hot summers have a positive effect on individuals' perceptions of anthropogenic global warming, and there is a hint that cooling spring temperatures may have an effect on global warming perceptions under some circumstances. Indeed, we find that coupling summer warming trends and spring cooling trends has a strong, discernible effect on individuals' perceptions of global warming. Specifically, individuals who reside in communities that combine summer warming trends and spring cooling trends are significantly more likely to perceive that global warming is due to human activity. This suggests that the effects of warming summer temperatures should be viewed in the context of trends in spring temperatures. It also indicates that the experience of contrast in seasonal temperatures has a stronger effect on perceptions of global warming than that of simple trends or short-term means. We are at an early stage of exploring the effects of climate and weather on perceptions of global warming, and we suggest that the finding of a strong effect of seasonal contrast (e.g., between Spring and Summer temperature trends) should generate further research. On the other hand, it seems that seasonal precipitation trends and short-term weather fluctuations do not have significant effects on public perceptions of global warming. It is possible that these effects of these variables vary considerably across contexts, and we suggest that the possibility of heterogeneous effects across contexts certainly warrants further study in the future.

Second, we explore the degree to which individuals' perceptions of global warming are determined by how individuals perceive scientists and science, as well as how individuals evaluate the role of science in American society. The claims that global temperatures are rising and that global warming is a result of human activity are generated through scientific activity conducted by scientists. We suggest that the degree to which individuals trust the work of scientists, have positive views about the contributions made by scientists and science, and correctly perceive the scientific consensus about global warming will be positively related to their propensity to perceive that anthropogenic global warming is taking place. Our empirical findings provide strong support for our assertions about the effects of attitudes about scientists and science influence individuals' perceptions of global warming. This conclusion is both good and bad news to scientists. From a positive perspective, advocates of global climate change can direct their efforts toward the establishment of positive images of scientists, and this may serve to make their research conclusions more convincing and acceptable to the public. The bad news is that any event such as "Climategate" or a careless paragraph about Himalayan ice melting could lead to mistrust of scientists' findings on 
global warming. Due to what global warming skeptics purport to be mistakes made by some climate scientists, the entire scientific community — and the case for anthropogenic global warming—is still recovering from the adverse effects of these perceived missteps.

Third, we confirm the findings from previous research that global warming has become highly politicized. Political ideology and party identification are strong significant predictors of individuals' perceptions of global warming; conservatives and Republicans tend to be significantly more skeptical of anthropogenic global warming than liberals and Democrats, who are more likely to accept the idea that global warming is due to human activity. Moreover, we find that the effect of education on perceptions of anthropogenic global warming is conditioned by partisan identification; the relationship is positive for Democrats but statistically indistinguishable from 0 for Republicans. Our results support the hypothesis that people rely on their political predispositions when they interpret evidence about global warming.

Fourth, we find some evidence of an effect of religion variables, particular in terms of our finding that white evangelical Protestants differ from several other groups. White evangelical Protestants differ from other religious groups in their perception of anthropogenic climate change, though many of these differences disappear in full models that include a wide range of control variables. With the recent release of the papal encyclical on climate change, the role of religion in shaping debates about global warming promises to be a subject of interest to scholars interested in the determinants of attitudes toward climate change.

Fifth, our findings confirm to a large extent the results of previous research about the effects of demographic attributes on attitudes toward and perceptions of global warming. We find that age, gender, and income all have effects on perceptions of anthropogenic global warming that are consistent with those reported in prior research, though (surprisingly) we find that race is unrelated to perceptions of global warming. We also find little evidence that the information environment influences perceptions of global warming, though our findings relating to education are consistent with expectations.

Finally, it is worth noting that the effects of our independent variables on perceptions of "natural cycle" global warming usually differ from the effects of our independent variables on perceptions of anthropogenic global warming. Variables that have a positive effect on the probability that individuals perceive that global warming is due to human activity have a negative effect on the probability that individuals perceive that global warming is due to natural cycles. Indeed, it would appear that perceptions of "natural cycle" global warming behave more similarly to 
perceptions of no global warming than to perceptions of anthropogenic global warming. It may be that perceptions of "natural cycle" global warming represent a middle ground for those who are somewhat skeptical of the scientific consensus about the causes of global warming but who perceive that global warming is occurring.

Our analyses are limited in some ways. First, our dependent variable is based on a series of questions that are commonly asked in surveys on climate change and global warming. However, it is possible that individuals who perceive that climate change is occurring may perceive that both natural cycles and human activity account for

Our analyses are limited in some way, and the research agenda on public opinion toward global warming is subsequently a full one. Where do we go from here? First, our dependent variable is based on a series of questions that are commonly asked in surveys on climate change and global warming. However, it is possible that there is more nuance to individuals' attitudes about the causes of climate change. Individuals who perceive that climate change is occurring may perceive that both natural cycles and human activity account for at least some of the variability of weather and climate over time. Our present measurement strategy assumes a discrete "either-or" process, but individuals may weight these two sets of causes differently. In future research we hope to develop survey questions to explore more fully the relative weight that individuals give to these two potential causes of climate change. Second, more work is needed on the connections between objective long- and short-term weather patterns and individuals' perceptions of those weather patterns. Do individuals who live in communities or regions that experience upward temperature or precipitation trends accurately perceive those trends? Do the perceptions of those trends then influence perceptions of global warming? Third, how do Republicans/conservatives and Democrats/liberals associate climate and weather with their perceptions of global warming? Do they respond differently or similarly to long-term climate trends and short-term weather fluctuations when they make judgments on global warming? Fourth, does weather and climate affect behavior relating to climate change? How do weather and climate affect individuals' willingness to engage in action touted by scientists and policy makers to combat climate change? It is important for scholars to explore more fully the determinants of attitudes toward policies designed to alleviate global warming in the long run. To what extent are Americans willing to take on what economists describe as the considerable costs of combating global warming? Will Americans support a carbon tax and/or higher taxes on goods and services that contribute to climate change? To what extent will Americans "buy in" to policies that many scientists contend will have the effect of reducing the human contributions to climate change? 


\section{ENDNOTES}

1. We note at the outset that we use the terms "climate change" and "global warming" interchangeably throughout the paper. Many observers prefer the term "climate change," though survey data used in this paper are based on survey questions that refer to "global warming." Further, we note the different definitions of "weather" and "climate." By "weather," we mean patterns of temperature, precipitation, and other atmospheric conditions that occur in the short term (i.e., today, over the past few days, or over the past week) at a location or in a specific geographic area. By "climate," we refer to general, longer-term patterns (i.e., over months or years) of weather that characterize a location or geographic area.

2. We also create variables that measure seasonal temperature trends over the past 40 years, 30 years, 20 years, 10 years, and five years. Our results suggest that seasonal temperature trends over the past 10 years yield the strongest empirical results. The results indicate that individuals are most responsive to 10-year trends than long-term trends for other durations.

3. There is some evidence that winter and summer temperatures are particularly relevant as determinants of individuals' perceptions of global warming. As noted in Hamilton and Keim (2009), warming winter temperatures in snow country are associated with public perceptions of global warming. This suggests that individuals who experience rising winter temperatures in their home communities over the past 10 years are more likely to believe that global warming is occurring and mainly human induced. On the other hand, in warmer parts of the country summer may be the season in which people are most aware of rising temperatures because of the greater discomfort from summer heat and the need for more air conditioning. This suggests that individuals who experience increasingly hot summers in their local communities over the past decade are more likely to perceive global warming and tend to attribute global warming to anthropogenic causes.

4. It is important to note that our measure of "short-term" temperature and precipitation fluctuations are different than those reported in the literature, most notably in the work of Egan and Mullin (2012) and Hamilton and Stampone (2013). In both of these works the authors use daily data to create a measure of short-term temperature and/or precipitation in the week (Egan and Mullin) or two-day period prior to or including the survey interview. Our "short-term" measure captures temperature and precipitation fluctuations over the longer time period of a single month.

5. We conduct regression diagnostics for multicollinearity among the independent variables for each model presented in this study. In no case are the variance inflation factors (VIFs) sufficiently large to suggest that this is a matter of concern.

6. We also estimate a model that includes only religion variables (results not shown), and we find that the coefficients for all of the religion variables (except the Mormon variable) are positive and statistical significant. This indicates that all religious groups are more likely to perceive anthropogenic climate change than white evangelical Christians, though these effects disappear for several religious groups once the effects of control variables are introduced into the model.

7. We also consider whether there is an interaction between gender and race, but the coefficient for this interaction variable is small and statistically insignificant $(b=0.027, \mathrm{z}=0.10)$. Hence it appears that there is a general gender effect but not a specific white male effect. 
Table 1. Ordered logit estimates for models of perceptions about global warming, as a function of attitudes, politics, information, demographics and climate. Data source: 2009 Pew General Public Science Survey

\begin{tabular}{|c|c|c|c|c|}
\hline \multirow[b]{2}{*}{ Variable } & \multicolumn{2}{|c|}{ Model (1) } & \multicolumn{2}{|c|}{ Model (2) } \\
\hline & $\mathrm{b}$ & Z & $b$ & Z \\
\hline \multicolumn{5}{|l|}{ Climate: 10 -year temperature trends } \\
\hline Winter $[+]$ & --- & --- & -0.027 & -0.75 \\
\hline Spring [+] & --- & --- & -0.159 & -1.88 \\
\hline Summer $[+]$ & --- & --- & 0.123 & $1.74^{*}$ \\
\hline Fall $[+]$ & --- & --- & 0.074 & 0.93 \\
\hline \multicolumn{5}{|l|}{ Climate: 10 -year precipitation trends } \\
\hline Winter [+/-] & --- & --- & -0.002 & -0.31 \\
\hline Spring [+/-] & --- & --- & 0.006 & 1.02 \\
\hline Summer [+/-] & --- & --- & 0.001 & 0.11 \\
\hline Fall [+/-] & --- & --- & -0.006 & -0.75 \\
\hline \multicolumn{5}{|l|}{ Weather: short-term fluctuation } \\
\hline Departure from normal temperature $[+]$ & --- & --- & 0.040 & 0.26 \\
\hline Departure from normal precipitation [+ / - ] & --- & --- & -0.124 & -1.47 \\
\hline \multicolumn{5}{|l|}{ Attitudes toward scientists and science } \\
\hline Scientists' contributions [+] & 0.337 & $2.71^{* * *}$ & 0.309 & $2.12 *$ \\
\hline Scientists ideology [+] & 0.259 & $2.12^{*}$ & 0.267 & $2.03^{*}$ \\
\hline Scientists' consensus [+] & 1.577 & $11.37^{* * *}$ & 1.586 & $11.28 * * *$ \\
\hline Science effects [+] & -0.051 & -0.68 & -0.050 & -0.55 \\
\hline Investment in science [+] & 0.721 & $4.22 * * *$ & 0.790 & $4.08^{* * *}$ \\
\hline \multicolumn{5}{|l|}{ Political Predispositions } \\
\hline Liberal-conservative ideology [-] & -0.283 & $-3.46^{* * *}$ & -0.298 & $-3.46^{* * *}$ \\
\hline Partisan identification [-] & -0.045 & -0.36 & -0.029 & -0.24 \\
\hline Education $[+]$ & 0.257 & $3.98 * * *$ & 0.244 & $3.92^{* * *}$ \\
\hline Partisan identification * education [-] & -0.062 & $-2.50 * *$ & -0.064 & $-2.69 * *$ \\
\hline \multicolumn{5}{|l|}{ Religion variables } \\
\hline Black Protestant [+] & -0.438 & -1.23 & -0.470 & -1.22 \\
\hline Mainline Protestant [+] & 0.769 & $3.38 * * *$ & 0.749 & $2.97 * *$ \\
\hline Catholic $[+]$ & 0.168 & 0.86 & 0.185 & 0.85 \\
\hline Other Christian [+] & 0.152 & 0.56 & 0.154 & 0.54 \\
\hline Jewish $[+]$ & 1.122 & $1.80 *$ & 1.094 & $2.24 *$ \\
\hline Mormon [+/-] & 1.218 & $2.09 *$ & 0.770 & 1.07 \\
\hline Other religion [+/-] & 0.568 & 1.20 & 0.463 & 1.00 \\
\hline Secular $[+]$ & 0.153 & 0.62 & 0.159 & 0.56 \\
\hline Church attendance [-] & -0.025 & -0.48 & -0.005 & -0.09 \\
\hline
\end{tabular}


Table 1 (continued)

\begin{tabular}{|c|c|c|c|c|}
\hline \multirow[b]{2}{*}{ Variable } & \multicolumn{2}{|c|}{ Model (1) } & \multicolumn{2}{|c|}{ Model (2) } \\
\hline & $\mathrm{b}$ & z & $\mathrm{b}$ & Z \\
\hline \multicolumn{5}{|l|}{ Information environment } \\
\hline Scientific knowledge [+] & 0.211 & 1.36 & 0.216 & 1.22 \\
\hline Church attendance [-] & -0.025 & -0.48 & -0.005 & -0.09 \\
\hline General media use [+/-] & 0.003 & 0.04 & 0.010 & 0.12 \\
\hline Scientific media use $[+/-]$ & -0.032 & -0.48 & -0.038 & -0.59 \\
\hline \multicolumn{5}{|l|}{ Demographic attributes } \\
\hline Age $[-]$ & -0.009 & $-2.17^{*}$ & -0.010 & $-2.22 *$ \\
\hline Gender [+] & 0.295 & $2.12^{*}$ & 0.283 & $1.90^{*}$ \\
\hline Income [-] & -0.061 & $-1.83^{*}$ & -0.060 & $-1.72 *$ \\
\hline White [-] & -0.296 & -1.28 & -0.337 & -1.19 \\
\hline $\mathrm{N}$ & \multicolumn{2}{|c|}{1161} & \multicolumn{2}{|c|}{1143} \\
\hline Pseudo $\mathrm{R}^{2}$ & \multicolumn{2}{|c|}{0.226} & \multicolumn{2}{|c|}{0.233} \\
\hline Wald $\chi^{2}$ & \multicolumn{2}{|c|}{500.31} & \multicolumn{2}{|c|}{439.58} \\
\hline $\operatorname{Prob}\left(\chi^{2}\right)$ & \multicolumn{2}{|c|}{0.0000} & \multicolumn{2}{|c|}{0.0000} \\
\hline
\end{tabular}

${ }^{* * *}$ prob $<0.001$ (one-tail test) $\quad * *$ prob $<0.01$ (one-tail test) $\quad *$ prob $<0.05$ (one-tail test)

Note: Z-statistics in Model (2) are based on standard errors estimated with clustering by weather station. The constant terms are omitted from the table for the sake of brevity. 
Table 2. Ordered logit estimates for models of individuals' perceptions of global warming, with variable for spring-summer temperature trend difference, 2009 Pew General Public Science Survey

$\begin{array}{lll}\text { Variable } & \text { b } & \text { Z }\end{array}$

Climate: 10-year temperature trends

Spring-summer trend difference [+]

$0.145 \quad 2.70 * *$

Attitudes toward scientists and science

Scientists' contributions [+]

$0.3112 .14^{*}$

Scientists ideology [+]

$0.2541 .95 *$

Scientists' consensus [+]

Science effects [+]

$1.583 \quad 11.29 * * *$

Investment in science [+]

$-0.056-0.63$

Political Predispositions

Liberal-conservative ideology [-]

$0.782 \quad 4.09 * * *$

Partisan identification [-]

$-0.307$

$-0.043$

$-3.61 * * *$

Education [+]

$0.247 \quad 3.98 * * *$

Partisan identification * education [-]

$-0.061-2.58 * *$

Religion variables

Black Protestant [+]

$-0.553$

$-1.47$

Mainline Protestant [+]

0.706

$2.83 * *$

Catholic [+]

0.162

0.77

Other Christian [+]

0.140

0.49

Jewish [+]

Mormon [+/-]

1.091

$2.32 * *$

Other religion [+/-]

0.810

1.16

Secular [+]

0.476

1.02

Church attendance [-]

0.125

0.44

$-0.008$

$-0.14$

Information environment

Scientific knowledge [+]

0.221

0.006

1.25

General media use [+/-]

$-0.034$

0.07

Scientific media use [+/-]

$-0.53$

Demographic attributes

Age [-]

$-0.010$

$-2.22 *$

Gender [+]

0.277

1.87*

Income [-]

$-0.062$

$-1.78 *$

White [-]

$-0.357$

$-1.26$ 
Table 2 (continued)

$\begin{array}{ll}\mathrm{N} & 1143 \\ \text { Pseudo } \mathrm{R}^{2} & 0.231 \\ \text { Wald } \chi^{2} & 424.61 \\ \text { Prob }\left(\chi^{2}\right) & 0.0000 \\ & \\ * * * \text { prob }<0.001 \text { (one-tail test) } \quad * * \text { prob }<0.01 \text { (one-tail test) } & * \text { prob }<0.05 \text { (one-tail test) }\end{array}$

Note: Z-statistics are based on standard errors estimated with clustering by weather station. The constant terms are omitted from the table for the sake of brevity. 


\section{REFERENCES}

Benetsky, Megan J., Charlynn Burd, and Melanie Rapino, 2015. "Young Adult Migration: 2007-2009 to 2010-2012," American Community Survey Reports, ACS-31, U.S. Census Bureau, Washington, DC,

Borick, C. P. \& B. G. Rabe. 2010. “A Reason to Believe: Examining the Factors that Determine Individual Views on Global Warming.” Social Science Quarterly 91: 777-800.

Boykoff, M. T. 2008. "Media and Scientific Communication: A Case of Climate Change.” Geological Society 305: 1118.

Boykoff, M. T. and J. M. Boykoff. 2004. "Balance as Bias: Global Warming and the U.S. Prestige Press." Global Environmental Change-Human and Policy Dimensions 14: 125-136.

Brody, S. D., S. Zahran, A. Vedlitz\& H. Grover. 2008. "Examining the Relationship Between Physical Vulnerability and Public Perceptions of Global Climate Change in the United States." Environment and Behavior 40: 72-95.

Dietz, T., A. Dan and R. Shwom. 2007. "Support for Climate Change Policy: Social Psychological and Social Structural Influences. Rural Sociology 72: 185-214.

Dunlap, R.E. 1998. “Lay Perceptions of Global Risk - Public Views of Global Warming in Cross-National Context."International Sociology 13: 473-498.

Dunlap, R. E. and A. M. McCright. 2008. “A Widening Gap - Republican and Democratic views on Climate Change.” Environment 50: 26-35.

Egan, Patrick J. and Megan Mullin. 2012. "Turning Personal Experience into Political Attitudes: The Effect of Local Weather on Americans' Perceptions about Global Warming.” Journal of Politics 79: 796-809.

Finucane, M. L., P. Slovic, C. K. Mertz, J. Flynn, and T. A. Satterfield. 2000. “Gender, Race, and Perceived Risk: The 'White Male' Effect. Health Risk and Society 2: 159-172.

Funk, Cary, Lee Rainie, and Dana Page. 2015. "Public and Scientists' Views on Science and Society.” Pew Research Center report, available at http://www.pewinternet.org/files/2015/01/PI_ScienceandSociety_Report_012915.pdf. Gomez, Brad T., Thomas G. Hansford, and George A. Krause. 2007. "The Republicans Should Pray for Rain: Weather, Turnout, and Voting in U.S. Presidential Elections." Journal of Politics 69: 649-663.

Hamilton, L. C. 2008. “Who Cares about Polar Region?” Arctic, Antarctic, and Alpine Research 40: 671-8. Hamilton, L.C. 2011. "Education, Politics, and Opinions about Climate Change: Evidence for Interaction Effects. Climatic Change 104: 231-242. 
Hamilton, L.C. 2012. "Did the Arctic ice recover? Demographics of true and false climate facts." Weather, Climate, and Society 4(4):236-249. doi: 10.1175

Hamilton, L. C. and B. D. Keim. 2009. "Regional Variation in Perceptions about Climate Change." International Journal of Climatology 29: 2348-2352.

Hamilton, L. C. and M. D. Stampone. 2013. "Blowin' in the wind: Short-term weather and belief in anthropogenic climate change." Weather, Climate, and Society doi: 10.1175/WCAS-D-12-00048.1

IPCC. 2013. Summary for Policymakers. In: Climate Change 2013: The Physical Science Basis. Contribution of Working Group I to the Fifth Assessment Report of the Intergovernmental Panel on Climate Change [Stocker, T.F., D. Qin, G.-K. Plattner, M. Tignor, S.K. Allen, J. Boschung, A. Nauels, Y. Xia, V. Bex and P.M. Midgley (eds.)]. Cambridge University Press, Cambridge, United Kingdom and New York, NY, USA.

Howe, P., E. Markowitz, T.M. Lee, C.Y. Ko, and A. Leiserowitz, 2013. “Global perceptions of local temperature change." Nature Climate Change 3: 352-356.

Kahan, D.M., H. Jenkins-Smith, and D. Braman. 2011. "Cultural cognition of scientific consensus.” Journal of Risk Research 14(2):147-174.

Karl, T. R., J.M. Melillo, and T.C. Peterson. 2009. Global Climate Change Impacts in the United States. New York: Cambridge University Press.

Kellstedt, P. M., S. Zahran and A. Vedlitz. 2008. "Personal Efficacy, the Information Environment, and Attitudes Toward Global Warming and Climate Change in the United States.” Risk Analysis 28: 113-126.

Krosnick, J. A. and D. F. Alwin. 1987. “An Evaluation of a Cognitive Theory of Response Order Effects in Survey Measurement." Public Opinion Quarterly 51: 201-219.

Krosnick, J. A., A. L. Holbrook, L. Lowe and P. S. Visser. 2006. "The Origins and Consequences of Democratic Citizens' Policy Agendas: A Study of Popular Concern about Global Warming.” Climatic Change 77: 7-43.

Leiserowitz, A. 2006. “Climate Change Risk Perception and Policy Preferences: The Role of Affect, Imagery, and Values." Climatic Change 77: 45-72.

Lorenzoni, Irene and Nick Pidgeon.2006. "Public Views on Climate Change: European and USA Perspectives." Climatic Change 77: 73-95.

Malka, A., J. A. Krosnick, and G. Langer. 2009. "The Association of Knowledge with Concern About Global Warming: Trusted Information Sources Shape Public Thinking." Risk Analysis 29: 633-647. 
Marshall, B. K. 2004. “Gender, Race, and Perceived Environmental Risk: The 'White Male' Effect in Cancer Alley, LA.” Sociological Spectrum 24: 453-478.

McCright, A. M. and R. E. Dunlap. 2000. "Challenging Global Warming as a Social Problem: An Analysis of the Conservative Movement's Counter-Claims." Social Problems 47: 499-522.

McCright, A. M. and R. E. Dunlap. 2011a. "Cool Dudes: The Denial of Climate Change among Conservative White Males in the United States.” Global Environmental Change-Human and Policy Dimensions 21: 1163-1172.

McCright, A. M. and R. E. Dunlap.2011b. "The Politicization of Climate Change and Polarization in the American Public's Views of Global Warming, 2001-2010.”Sociological Quarterly 52: 155-194.

Nisbet, M. C. and T. Myers. 2007. "The Polls -Trends - Twenty Years of Public Opinion about Global Warming." Public Opinion Quarterly 71: 444-470.

Myers, T., E. Maibach, C. Roser-Renouf, K. Akerlof, and A. Leiserowitz. 2013. “The relationship between personal experience and belief in the reality of global warming." Nature Climate Change 3: 343-347.

Oreskes, N. 2004. “Beyond the Ivory Tower: The Scientific Consensus on Climate Change.” Science 306: 1686.

Pew Research Center. 2009. "May 2009 Science Survey.” http://www.people-press.org/2009/07/30/may-2009-sciencesurvey/.

Pew Research Center. 2012. "More Say There is Solid Evidence of Global Warming,” http://www.peoplepress.org/2012/10/15/more-say-there-is-solid-evidence-of-global-warming/.

Pew Research Center. 2013. “GOP Deeply Divided Over Climate Change,” http://www.peoplepress.org/2013/11/01/gop-deeply-divided-over-climate-change/.

Primo, D. M., M. L. Jacobsmeier and J. Milyo. 2007. "Estimating the Impact of State Policies and Institutions with Mixed-Level Data." State Politics and Policy Quarterly 7: 446-459.

Shao, Wanyun, Barry D. Keim, James C. Garand, and Lawrence C. Hamilton. 2014. "Weather, Climate, and the Economy: Explaining Risk Perceptions of Global Warmking, 2001-10.” Weather, Climate, and Society 6: 11934.

Solomon, S., D. Qin, M. Manning, Z. Chen, M. Marquis, K. B. Averyt, M. Tignor\& H. L. Miller. 2007. Contribution of Working Group I to the Fourth Assessment Report of the Intergovernmental Panel on Climate Change. Cambridge, United Kingdom and New York, NY, USA: Cambridge University Press. 
U.S. National Research Council. 2010. Advancing the Science of Climate Change. Washington, D.C.: National Academies Press.

Vanliere, K. D. and R. E. Dunlap. 1980. "The Social Bases of Environmental Concern—A Review of Hypotheses, Explanations, and Empirical Evidence.” Public Opinion Quarterly 44: 181-197.

Weber, E. U. 2010a. “What Shapes Perceptions of Climate Change?” Wiley Interdisciplinary Reviews-Climate Change 1: 332-342.

Wood, B. D. and A. Vedlitz. 2007. "Issue Definition, Information Processing, and the Politics of Global Warming." American Journal of Political Science 51: 552-568.

Zaller, J. R. 1992. The Nature and Origins of Mass Opinion.New York: Cambridge University Press. 